\title{
Fragrant films on the basis of potato starch
}

\author{
Ewa Drewnowska ${ }^{1}$, Adrian Krzysztof Antosik ${ }^{1^{*}}$, Agnieszka Wróblewska $^{1^{*}}$, Zbigniew Czech $^{1}$, \\ Katarzyna Wilpiszewska ${ }^{2}$
}

\author{
${ }^{1}$ West Pomeranian University of Technology, Szczecin, Faculty of Chemical Technology and Engineering, Institute of \\ Organic Chemical Technology, Pułaskiego 10, 70-322 Szczecin, Poland \\ ${ }^{2}$ West Pomeranian University of Technology, Szczecin, Faculty of Chemical Technology and Engineering, Polymer Institute, \\ Pułaskiego 10, 70-322 Szczecin, Poland \\ *corresponding authors: e-mail: agnieszka.wroblewska@zut.edu.pl, adriankrzysztofantosik@gmail.com
}

\begin{abstract}
New fragrant and biodegradable starch-based films have been obtained. These films were prepared by the method of the outpour into the Teflon mould of the starch composition containing such fragrant compounds as: eugenol or $\alpha$-pinene. For characterizing the final products the following properties were taken into account: the solubility in water, the absorbance of moisture from air and the length of release of the fragrant compound. The obtained starch-based films were characterized by the relatively long time of release the fragrant compound and also by the good absorbance of moisture from air. Taking into account the properties of the obtained films, they can find applications in production of appliances used in the bioactive cleaning of air. The prototype of such a product was presented in this work. The presented studies show the potential of applying these materials in the future, and thus these examinations should be developed.
\end{abstract}

Keywords: fragrant starch-based films, biodegradability, starch, $\alpha$-pinene, eugenol.

\section{INTRODUCTION}

Starch was the first natural polymer used on the industrial scale. In 1939 it was applied for the control of the filtration of drilling fluids with considerable salt content. Starch is a natural polymer, which is a secondary material for plants. It is produced during the process of assimilation of carbon dioxide from air (photosynthesis) with the participation of chlorophyll. It is a white and an amorphous substance, without a taste and a smell. Starch is built of glucose constitutional units connected by $\alpha-1,4-$ glycoside bonds ${ }^{1-3}$. Taking into account its chemical structure it is ranked in the family of carbohydrates (sugars). Starch is the basic carbohydrate for human diet. It is obtained from fruits, bulbs and seeds such as: potatoes, grains, amaranth, mango, bananas, tapioca and leguminous plants. It is built from two polymers: in 20-25\% from amylose (a linear biopolymer, which forms in water a colloidal solution) and in 75-80\% amylopectin (a polymer which is insoluble in water). The ratio of these two polymers is changeable and it depends on the origin of $\operatorname{starch}^{4-6}$. Starch is an environmentally friendly substance. The native starch is insoluble in cold water and unstable at high temperatures. Starch on account of its non-toxicity, biological neutrality, biodegradability and biocompatibility, finds applications in the pharmaceutical industry as an auxiliary substance in production of pills, and also as a matrix, a binder or a filler, ${ }^{2,7}$. Owing to the fact that it has ability to gelation and modification of the texture of products, it finds also applications in food production (blancmanges, yoghurts, creams, mayonnaises and sauces $)^{4,8}$. Moreover, it is used in production of containers which are allowed to contact food ${ }^{7-8}$.

In the last decade the studies on the application of polysaccharides as potential substitutes for synthetic polymers in the plastics industry were intensified. Advantages connected with the application of biopolymer films are as follows: an environmental preservation, a low cost of the production and a relatively fast renewability of raw materials. These advantages cause that biopolymer films can be a good alternative to the conventional polymers based on compounds obtained from mineral oil. Films obtained on the basis of biopolymers are very often used in the production of containers. The presence of such modifiers as organic acids, enzymes or silver causes that these films have antibacterial properties ${ }^{9-11}$.

This work presents a method of obtaining new fragrant films with the utilization of two cheap and renewable fragrant compounds which are the components of biomass: $\alpha$-pinene and eugenol. These compounds can be obtained in a simple way from such renewable sources as: turpentine and buds of clove trees or from a waste - sulfite waste liquor, which is formed during the production of cellulose from wood ( $\alpha$-pinene). $\alpha$-pinene is the organic compound which belongs to the group of terpenes. It is separated from turpentine obtained from the pine resin. $\alpha$-Pinene is characterized by the antiseptic and the antibacterial activities (it damages membrane cells and hinders the synthesis of bacteria and fungi) ${ }^{\mathbf{1 2}}$. Moreover, it shows anticancer activity (it showed considerable activity in the hindering of the development of cancer cells of hepatoma BEL-7402) ${ }^{13}$. $\alpha$-pinene finds also many applications in: perfume-cosmetic industry (as the component and as the raw material for the obtaining of other fragrant compounds, $\alpha$-terpineol, limonene $)^{14}$, food industry ${ }^{14}$, pharmaceutical industry ${ }^{14}$, in aromatherapy ${ }^{14}$, in dyeing industry ${ }^{15}$ and as the anticancer agent in traditional Chinese medicine ${ }^{\mathbf{1 6}}$. Moreover, it is used in therapy of heart, bronchus and lungs diseases - it influences heart activity and blood circulation ${ }^{17}$ and it is used in the curing of sharp and chronic bronchitis and in inflammations of the nose mucous membrane ${ }^{18}$.

The second fragrant compound used in this work for the preparation of the fragrant films was eugenol. It is an organic compound which belongs to the cyclic terpene alcohols. Eugenol is the main component of clove oil (its content in clove oil reaches $92 \%)^{\mathbf{1 9}, 20}$. Clove oil has been used for the flavoring of foodstuffs, in the production of fragrant arrangements used in the perfume industry and also in the production of cosmetics and pharmaceutical 
preparations showing antiseptic activity (preparations for the oral cavity care or toothpastes) ${ }^{20}$. Clove oil as, pharmaceutical preparation show, has a relaxing, refreshing and deflavoring effect. It is also used as the disinfection agent for the digestive, gall, breathing and urinary systems, and moreover, eugenol can hinder a cough thus it can be used in cough syrups ${ }^{20}$.

Clove oil used directly on the skin and the mucous membrane warms up and relieves pain, reduces stress and helps in therapy of anxiety and depression states ${ }^{\mathbf{2 1}}$. Moreover, this oil enhances our immune system and helps in the elimination of various infections because eugenol, which is included in the clove oil, shows an antibacterial, antiviral and antifungal effect ${ }^{22,23}$. Furthermore, eugenol eliminates saprophytes and protozoa, and fends parasites off $^{21}$. It has the ability to capture and thus eliminate of free radicals which slows down the human organism aging process and decreases the risk of developing cancer ${ }^{19}$.

This work presents a method for the preparation of new fragrant films obtained with the participation of raw materials of natural origin: starch, $\alpha$-pinene and eugenol (Fig. 1).

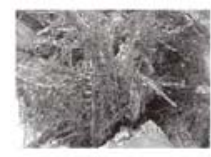

pinene

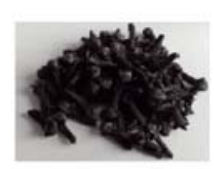

eugenol

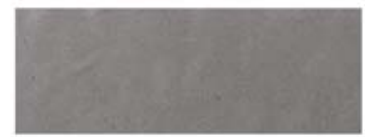

starch-based film with pinene

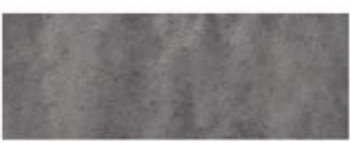

starch-based film with eugenol
Figure 1. Scheme of the preparation of the biodegradable fragrant film obtained on the basis of starch and described in this work

Our studies showed that the obtained films were characterized by their biodegradability, the relatively long time of release of the fragrant compound and the good absorbance of moisture. Taking into account possible future applications of such kinds of films, for example in air-fresheners which will show antibacterial and antifungal effect, and also can protect against saprophytes expansion in living quarters, these studies are worth continuing in other to develop better such films.

\section{EXPERIMENTAL}

\section{Material}

In the preparation of the starch films the following raw materials were used: starch (technical grade, Nowamyl S.A. Nowogard), glycerol (analytical grade, Chempur), $\alpha$-pinene (98\%, Aldrich) and eugenol ( $\geq 98 \%$, Sigma-Aldich).

\section{The preparation of the biodegradable fragrant films}

The biodegradable fragrant films were prepared by the method of the outpour of a solution which was followed by a solvent evaporation. The following raw materials were introduced into the glass reactor with the capacity of $250 \mathrm{~mL}: 200 \mathrm{~g}$ of deionized water, $2 \mathrm{~g}$ of glycerol and $3 \mathrm{~g}$ of starch. The mixture was stirred in a water bath at the temperature of $90^{\circ} \mathrm{C}$ until a homogeneous solution was obtained. Next, $2 \mathrm{~g}$ of the fragrant compound ( $\alpha$-pinene or eugenol) was introduced. The mixture was stirred for 30 minutes until the homogeneous mixture was obtained, and next this mixture was outpoured into the Teflon mould. The mould was put into a dryer for $48 \mathrm{~h}$ at the temperature of $70^{\circ} \mathrm{C}$. The prepared film (thickness 200-300 mm) was then taken from the mould (Figs. 2-3).

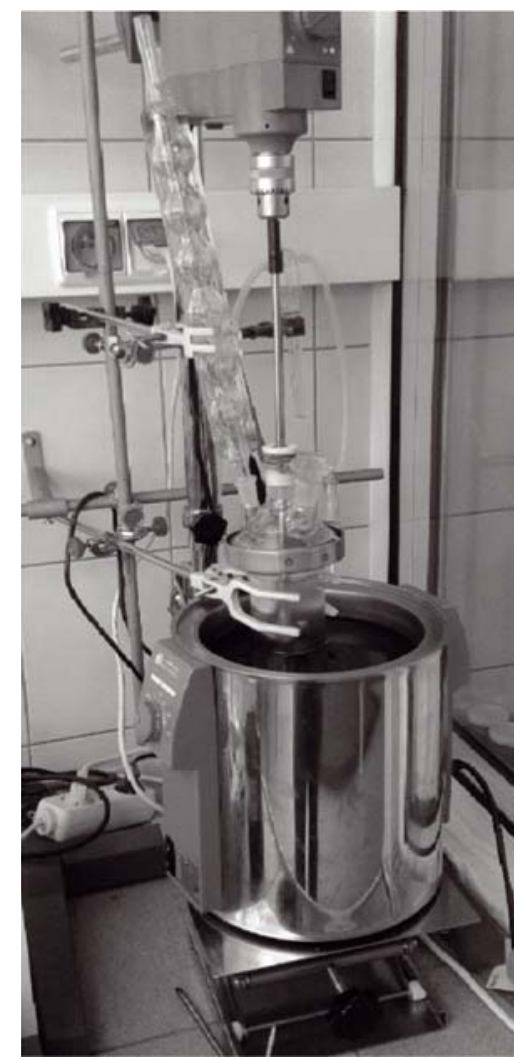

Figure 2. Reactor with mechanical stirrer

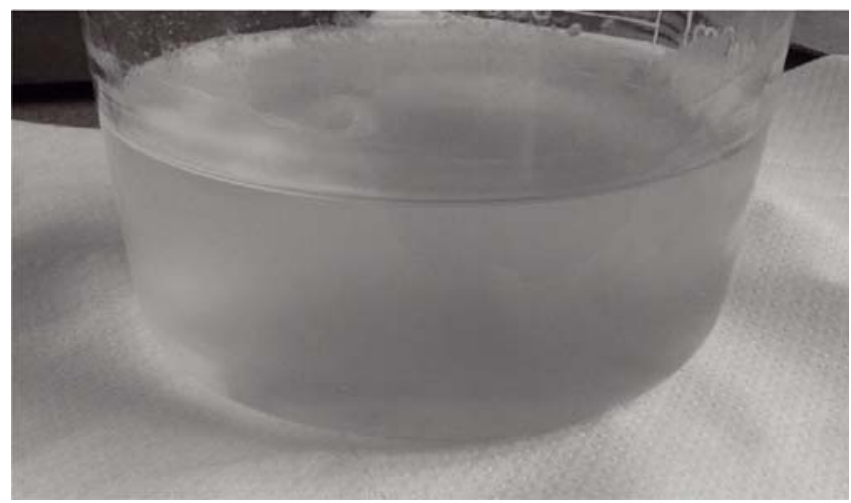

Figure 3. Homogeneous mixture which was outpoured into the Teflon mould and from which fragrant film was obtained

For studies on the solubility of the obtained films in water 3 squares, each with the size of $1.5 \mathrm{~cm}$, were cut from the film. These squares were put into the desiccator for two weeks to remove moisture. Next, samples were weighted, put into the vials and flooded with $50 \mathrm{~mL}$ of deionized water. After $24 \mathrm{~h}$ samples were taken from water, dried preliminary and put into the dryer at $60^{\circ} \mathrm{C}$ for $24 \mathrm{~h}$. Dry samples were again weighed. The results were put into the following formula ${ }^{11-12}$. 
$T S M=\frac{M_{1}-M_{2}}{M_{1}} \cdot 100 \%$

where: TSM (Total Soluble Mater) - content of soluble part (solubility in water) [\%]; $\mathrm{M}_{1}$ - mass of preliminary dried sample [g]; $\mathbf{M}_{2}-$ mass of sample after drying [g].

Similar studies were performed for films kept in water for 7 and 14 days.

Moisture absorption tests were performed for each film as follows. Three samples $(1.5 \mathrm{~cm} \times 1.5 \mathrm{~cm})$ were prepared and placed for two weeks in the desiccator to dry. Dry samples were weighed and subsequently transferred to a climatic chamber $(55 \pm 2 \%$ humidity, $25 \pm 2^{\circ} \mathrm{C}$ ). The weight of tested samples was controlled at 3, 5, 7, 24, 48 and 72 hours after placing them in the climate chamber. Moisture absorption was calculated using the following equation ${ }^{\mathbf{1 1 - 1 2}}$.

$A_{t}=\frac{M_{t}-M_{0}}{M_{0}} \cdot 100 \%$

where: $\mathrm{A}_{\mathrm{t}}-$ moisture absorption after time $\mathrm{t}[\%] ; \mathrm{M}_{0}-$ mass of dry sample [g]; $\mathrm{M}_{\mathrm{t}}$ - mass of sample after time $\mathrm{t}: 3,5,7,24,48$ and $72 \mathrm{~h}$ [g].

The organoleptic tests have been performed for 3 months. Biodegradable films with the mass of $10 \mathrm{~g}$ were introduced into the specially designed container with openings, and the scheme is presented in Figure 4 - dimensions are given in millimeters (equipment for bioactive refresh of air) and put in the closed room with the capacity of $100 \mathrm{~m}^{3}$. This container was built from a biodegradable polymer (polylactide), and with these materials all this equipment after application can be re-utilized and thus this container is safe for the environment. The intensity of the smell of the films was tested after 1 h, 24 h, 7 days, 14 days, 1 month, 2 months and 3 months. For comparison smell intensity was related to the samples of the same weight sealed in vials with the capacity of $30 \mathrm{~mL}$.

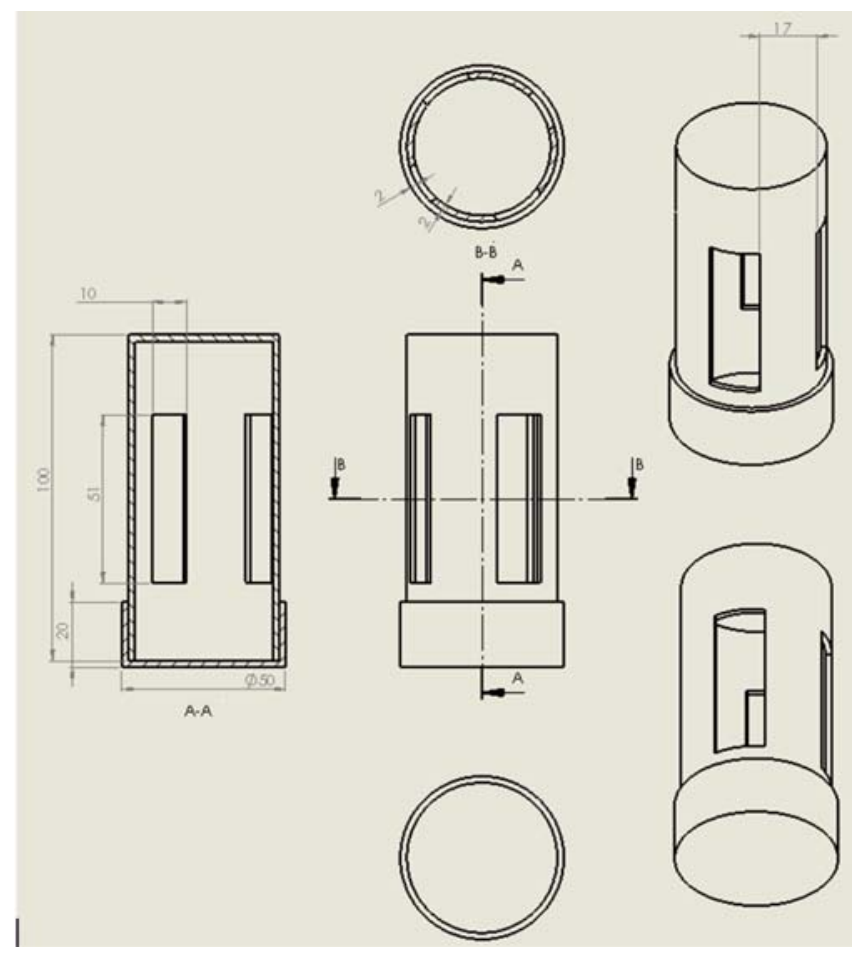

Figure 4. Scheme of the equipment for the bioactive cleaning of air which was used in organoleptic tests
In order to check whether fragrant compounds ( $\alpha$-pinene, eugenol) are washed out by water after a certain period of time the chromatographic analyses were performed. The cut samples of films with size of $1.5 \mathrm{~cm} \times 1.5 \mathrm{~cm}$ were introduced into a container and covered with $50 \mathrm{~mL}$ of water. The container was then sealed. Subsequently, after 24 hours, 7 days and 14 days representative samples from the whole volume with the mass of $2 \mathrm{~g}$ were taken. These samples were analyzed by the gas chromatography method. The gas chromatography analyses were performed on the FOCUS apparatus equipped with a FID detector and a capillary Quadrex column $30 \mathrm{~m}$ x $250 \mu \mathrm{m}$ x $0.25 \mu \mathrm{m}$ filled with methylsiloxane modified with phenyl groups. The parameters of the separation were as follows: pressure of helium - $45 \mathrm{kPa}$, sample chamber temperature 150 , detector temperature 250 , oven temperature program: isothermally at 60 for $1 \mathrm{~min}$, increase temperature with the rate of $15 / \mathrm{min}$, isothermally at 200 for $8 \mathrm{~min}$, cooling to 60 , sensitivity -100 and volume of the sample $4 \mu \mathrm{L}$. The similar procedure was used in the case of ethanol. The results have been calculated quantitatively to the mass of the sample.

\section{RESULTS AND DISCUSSION}

Biodegradable fragrant films on the basis of starch and contain $\alpha$-pinene or eugenol have been obtained. It was observed that with the increase of the residence time of the film in water, the degree of solubility of the studied films increased (Fig. 5). Films showed high degree of solubility (about $50 \%$ after $24 \mathrm{~h}$ ). It is connected with high plasticizer content (glycerol) in the studied material, which is eluted first. Water, in which films were dissolved, showed the smell of used fragrant compounds (organoleptic studies) and it was further analyzed (chromatographic analyses) (Table 1).

Table 1. Solubility of the biodegradable fragrant films in dependence on the time

\begin{tabular}{|l|c|c|c|}
\hline \multirow{2}{*}{ Type of film } & \multicolumn{3}{|c|}{ Solubility after appropriate time [\%] } \\
\cline { 2 - 4 } & $24 \mathrm{~h}$ & 7 days & 14 days \\
\hline $\begin{array}{l}\text { Starch + Eugenol } \\
\text { (5S 3,33G 3,33E) }\end{array}$ & $48.7 \pm 0.1$ & $69.1 \pm 0.1$ & $72.1 \pm 0.1$ \\
\hline $\begin{array}{l}\text { Starch + } \alpha-P i n e n ~ e \\
\text { (3S 3,33G 2P) }\end{array}$ & $48.1 \pm 0,1$ & $65.5 \pm 0.1$ & $68.3 \pm 0.1$ \\
\hline
\end{tabular}

Symbols: S - starch, G - glycerol, E - eugenol, P - $\alpha$-Pinene

Figure 6 presents moisture absorption tests for fragrant films with $\alpha$-pinene and eugenol. For both fragrant compounds very similar increases of moisture in time was observed. For both systems after $72 \mathrm{~h}$ moisture absorption was on the level of about $15 \%$.

Organoleptic tests made it possible to state clearly that the obtained biodegradable films show a long release of aroma which allows the slow and prolonged propagation of this aroma in a room (Table 2). This may be due to the fact that the eugenol and $\alpha$-pinene are trapped inside the studied films, which slowly transmits them out.

The performed GC analyses revealed that aromatic compounds ( $\alpha$-pinene and eugenol) present in the films were washed in a small amount after $24 \mathrm{~h}$, for example

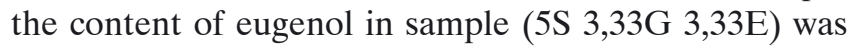
$0.0068 \mathrm{wt} \%$, while the content of $\alpha$-pinene in sample 
Table 2. Intensity of aroma of the studied samples for the appropriate reaction time

\begin{tabular}{|l|c|c|c|c|c|c|c|}
\hline \multirow{2}{*}{ Type of film } & \multicolumn{7}{|c|}{ Intensity of the aroma after the appropriate time } \\
\cline { 2 - 7 } & $1 \mathrm{~h}$ & $24 \mathrm{~h}$ & 7 days & 14 days & 1 months & 2 months & 3 months \\
\hline $\begin{array}{l}\text { Starch + Eugenol } \\
(5 \mathrm{~S} 3,33 \mathrm{G} 3,33 \mathrm{E})\end{array}$ & identical & identical & identical & identical & identical & identical & \multirow{2}{*}{ weaker } \\
\hline $\begin{array}{l}\text { Starch }+\alpha-\text {-Pinene } \\
(3 \mathrm{~S} 3,33 \mathrm{G} 2 \mathrm{P})\end{array}$ & identical & identical & identical & identical & identical & weaker & weaker \\
\hline
\end{tabular}

Symbols: S - starch, G - glycerol, E - eugenol, P - $\alpha$-Pinene

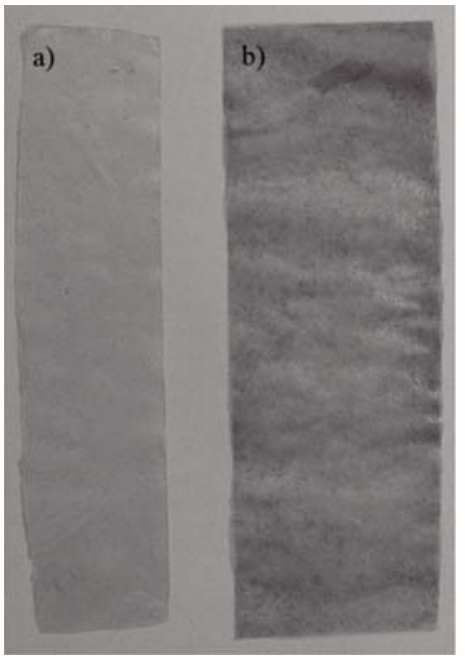

Figure 5. Biodegradable fragrant films with: a) $\alpha$-pinene and b) eugenol

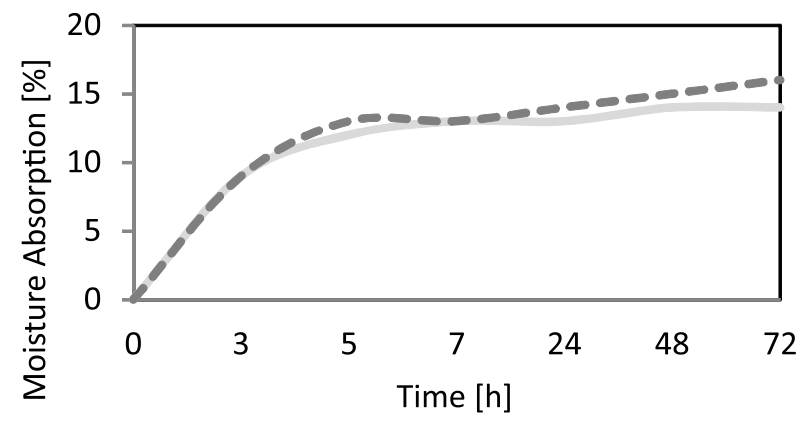

- Film with eugenol $-\square-$ Film with pinene

Figure 6. Moisture absorption tests (dependence on time)

(3S 3,33G 2P) was $0.0003 \mathrm{wt} \%$. After 7 days the content of eugenol and $\alpha$-pinene in samples slightly increased,

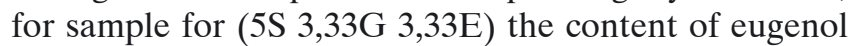
was $0.007 \mathrm{wt} \%$, while the content of $\alpha$-pinene in sample (3S 3,33G 2P) was $0.00009 \%$ Subsequently after 14 days the contents of the compounds in the samples increased (Table 3). Thus, the aromatic compounds are retained in the structure of the film structure and this results in long-term persistence of aroma.

\section{CONCLUSIONS}

Fragrant compounds (terpenes) can be very valuable additives for polymers, also such polymers which are obtained on the basis of compounds of natural origin. The addition of these substances not only gives polymers a pleasant smell, but also changes their properties, because terpenes in addition to a pleasant aroma are also characterized by the following action: fungicidal, bactericidal, anti-cancer and inhibit the growth of dust mites. These properties make that the new materials obtained on the basis of $\alpha$-pinene or eugenol may be used to treat various infections, including infections in the bronchi and lungs. Moreover, these materials may be useful in the treatment of asthma and cancer, and also heart diseases. The new product obtained with the utilization of terpenes in polymeric materials may also find applications in the production of packaging for food (protection against decay), in the cosmetics industry (face masks), for disinfect both homes and public institutions, including schools and hospitals, etc.

The studies presented in this work are preliminary with great development potential and broad possible applications. The possible applications of these new materials prove the necessity of further research in the direction of their improvement.

\section{LITERATURE CITED}

1. Turkiewicz, A. (2005). Doctoral dissertation - Some problems of degradation water-dispersion polymer drilling fluids (in Polish). AGH im. Stanisława Staszica w Krakowie.

2. Romero-Bastida, C.A., Bello-Perez, L.A., Garcia, M.A., Martino, M.N., Solorza-Feria, J. \& Zaritzky, N.E. (2005). Physicochemical and microstructural characterization of films prepared by thermal and cold gelatization from non-conventional sources of starches. Carbohyd. Polym., 60, 235-244. DOI: 10.1016/j.carbpol.2005.01.004.

Table 3. Results of studies on washing of eugenol and $\alpha$-pinene from films for the appropriate reaction time

\begin{tabular}{|c|c|c|c|c|c|c|}
\hline \multirow[t]{2}{*}{ Time } & \multicolumn{2}{|c|}{ After $24 \mathrm{~h}$} & \multicolumn{2}{|c|}{ After 7 days } & \multicolumn{2}{|c|}{ After 14 days } \\
\hline & $\begin{array}{c}\text { Starch + } \\
\text { Eugenol } \\
(5 \mathrm{~S} 3,33 \mathrm{G} \\
3,33 \mathrm{E}) \\
\end{array}$ & $\begin{array}{c}\text { Starch + } \\
\alpha \text {-pinen } \\
(3 S 2 G 2 P)\end{array}$ & $\begin{array}{c}\text { Starch + } \\
\text { Eugenol } \\
(5 \mathrm{~S} 3,33 \mathrm{G} \\
3,33 \mathrm{E}) \\
\end{array}$ & $\begin{array}{c}\text { Starch + } \\
\alpha-\text {-pinen } \\
(3 S 2 G \text { 2P) }\end{array}$ & $\begin{array}{c}\text { Starch + } \\
\text { Eugenol } \\
(5 \mathrm{~S} 3,33 \mathrm{G} \\
3,33 \mathrm{E}) \\
\end{array}$ & $\begin{array}{c}\text { Starch + } \\
\alpha \text {-pinene } \\
(3 S 2 G \text { 2P) }\end{array}$ \\
\hline $\begin{array}{l}\text { The mass of the sample } \\
\text { solution [g] }\end{array}$ & 27.988 & 24.850 & 33.962 & 32.036 & 33.962 & 32.036 \\
\hline Eugenol content [wt\%] & 0.0068 & - & 0.021 & - & 0.022 & - \\
\hline Eugenol content [g] & 0.0019 & - & 0.007 & - & 0.008 & - \\
\hline$\alpha$-pinene content [wt $\%$ ] & - & 0.0003 & - & 0.0004 & - & 0.0005 \\
\hline$\alpha$-pinene content [g] & - & 0.00008 & - & 0.00009 & - & 0.0001 \\
\hline Glycerol content [wt $\%$ ] & 0.0505 & 0.3250 & 0.210 & 0.184 & 0.180 & 0.062 \\
\hline Glycerol content [g] & 0.005 & 0.032 & 0.024 & 0.018 & 0.001 & 0.006 \\
\hline
\end{tabular}


3. Sindhu, M., Brahmakumar, M. \& Emilia Abgraham, T. (2006). Microstructural imaging and characterization of the mechanical, chemical, thermal and swelling properties of starch-chitosan blend films. Biopolym 82, 176-187. DOI: 10.1002/bip.20480.

4. Kittipongpatana, I.S., Chaichanasak, N., Kanchongkittipoan, S., Panturat, A., Taekanmark, T. \& Kittpongpatana, N. (2006). An aqueous film-coating formulation based on sodium carboxymethyl mungbean starch. Starch 58, 587-589. DOI: 10.1002/star.200600528

5. Silva, D.A., de Paula, R.C.M., Feitosa, J.P.A., de Brito, A.C.F., Maciel, J.S., Paula, H.C.B. (2004). Carboxymethylation of cashew tree exudate polysaccharide. Carbohydr. Polym. 58, 163-171. DOI: 10.1016/j.carbpol.2004.06.034.

6. Assaad, E. \& Mateescu, M.A. (2010). The influence of protonation ratio on properties of carboxymethyl starch excipient at various substitution degrees: Structural insights and drug release kinetics. Inter. J. Pharm. 394, 75-84. DOI: 10.1016/j.ijpharm.2010.04.037.

7. Spychaj T., Wilpiszewska K., Zdanowicz M. (2013). Medium and high substituted carboxymethyl starch: Synthesis, characterization and application. Starch 65, 22-33. DOI: 10.1002/star.201200159.

8. Malinowska-Pańczyk, E., Sztuka, K. \& Kołodziejska, I. (2010). Antimicrobial materials as components of the film based on biodegradable natural polimer (in Polish). Polimery $55,627-633$.

9. Talja, R.A., Helen, H., Roos, Y.H. \& Jouppila, K. (2007). Efect of various polyols and polyol contents on physical and mechanical properties of potato starch-based films. Carbohydr. Polym. 67, 288-295. DOI: 10.1016/j.carbpol.2006.05.019.

10. Wilpiszewska, K., Antosik, A.K. \& Spychaj, T. (2015). Novel hydrophilic carboxymethyl starch/montmorylonite nanocomposite films. Carbohydr. Polym., 128, 82-89. DOI: 10.1016/j. carbpol.2015.04.023.

11. Almasi, H., Ghanbarzadeh, B., Entezami, A.A. (2010). Physicochemical properties of starch-CMC-nanoclay biodegradable films. Inter. J. Bio. Macro. 46, 1-5. DOI:10.1016/j. ijbiomac.2009.10.001.

12. Kalemba, D. (1998). Antibacterial and antifungal properties of essential oils (in Polish). Post. Mikrobiol. 38, 165-184.

13. Chen, W., Liu, Y., Li, M., Mao, J., Zhang, L., Huang, R., Jin, X. \& Ye, L. (2015). Anti-tumor effect of $\alpha$-pinene on human hepatoma cell lines through inducing $\mathrm{G} 2 / \mathrm{M}$ cell cycle arrest. J. Pharm. Sci. 127(3), 332-338. DOI: 10.1016/j. jphs.2015.01.008

14. Swift, K.A.D. (2004). Catalytic Transformations of the Major Terpene Feedstocks. Top. Cat. 27, 143-155. DOI: 10.1023/B:TOCA.0000013549.60930.da.

15. Thomas, A.F. (1989). Limonene. Nat. Prod. Rep. 3, 291-309. DOI: 10.1039/NP9890600291.

16. Wang, C.Y., Bai, X.Y. \& Wang, C.H. (2014). Traditional Chinese medicine: a treasured natural resource of anticancer drug research and development. Am. J. Chin. Med. 42, 543-559. DOI: $10.1142 / \mathrm{S} 0192415 \mathrm{X} 14500359$.

17. Márcio, R.V., Santos Flávia, V. \& Moreira B.P. (2011). Cardiovascular effects of monoterpenes: a review. Rev. Bras. Farmacogn. 21, 764-771. DOI: 10.1590/S0102-695X2011005000119.

18. Suryawanshi, J.A.S. (2011). An overview of Citrus aurantium used in treatment of various diseases. Afr. J. Plant Sci. 5, 390-395.

19. Iversena, M., Finstada, B., McKinleyc, R.S. \& Eliassenb, R.A. 2003. The efficacy of metomidate, clove oil, Aqui- ${ }^{\mathrm{TM}}$ and Benzoak ${ }^{\circledR}$ as anaesthetics in Atlantic salmon (Salmo salar L.) smolts, and their potential stress-reducing capacity. Aquacult. 221, 549-566. DOI: 10.1016/S0044-8486(03)00111-X.

20. Bhowmik, D., Kumar, K.P.S. \& Yadav, A. (2012). Recent Trends in Indian Traditional Herbs Syzygium Aromaticum and its Health Benefits. J. Pharm. Phytochem. 1(1), 13-22.
21. Różański, H. (2016), Akademia Medyczna im. K. Marcinkowskiego, Zakład Historii Nauk Medycznych, Poznań: Essential oils as an alternative to antibiotic growth promoters and coccidiostats (in Polish). luskiewnik.strefa.pl. [2016-04-15].

22. Bakkali, F., Averbeck, S., Averbeck, D. \& Idaomar, M. (2008). Biological effects of essential oils - A review. Food Chem. Toxic. 46, 446-475. DOI: 10.1016/j.fct.2007.09.106.

23. Chaieb, K., Hajlaoui, H., Zmantar, T. \& Kahla-Nakbi, A.B. (2007). The chemical composition and biological activity of clove essential oil, Eugenia caryophyllata (Syzigium aromaticum L. Myrtaceae): a short review. Phytother. Res. 21, 501-506. DOI: $10.1002 /$ ptr.2124. 